\title{
RANCANG BANGUN SISTEM E-VOTING BERBASIS WEB
}

\author{
Charlene Alicia Wagiu dan Yulianus Palopak \\ Fakultas Teknologi Informasi, Universitas Advent Indonesia
}

\begin{abstract}
Abstrak
Proses pemilihan menjadi sangat penting dalam menentukan hasil yang diinginkan bagi para pemilih. Proses pemilihan sering terhambat dengan berbagai masalah salah satunya adalah proses pengumpulan dan penghitungan kembali suara yang membutuhkan waktu. Untuk itu perlu sebuah sarana yang dapat memfasilitasi proses pemilihan tersebut sehingga dapat memberikan hasil yang cepat dan akurat. Tujuan dari penelitian ini adalah membangun sebuah sistem yang dapat memberikan kemudahan bagi para mahasiswa Fakultas Teknologi Informasi UNAI dalam menjalankan proses demokrasi untuk memilih ketua Himpunan Mahasiswa. Sistem tersebut dirancang berbasis web sehingga akan lebih memudahkan dalam proses pengambilan, penghitungan suara hingga pengumuman pemenang yang terpilih. Metode yang digunakan dalam membangun sistem ini adalah menggunakan metode SDLC dengan model Waterfall yang terdiri dari tahapan-tahapan Analisis, Desain, Implementasi dan Pemeliharaan. Hasil dari rancang bangun sistem ini dapat digunakan dalam memilih pasangan ketua dan wakil ketua Himpuan Mahasiswa Fakultas Teknologi Informasi UNAI. Proses pemilihan dapat berjalan lebih tertib, teratur dan lebih cepat terutama dalam penghitungan suara pemilih serta pengumuman pemenang karena dilakukan melalui sistem. Diharapkan kedepannya sistem ini dapat dikembangkan dan diterapkan untuk proses pemilihan yang lain serta dapat dibuat pada platform yang lain.

Kata-kata kunci: pemilihan, e-voting, himpunan mahasiswa, web desain.
\end{abstract}

\section{E-VOTING SYSTEM DESIGN BASED ON WEB}

\begin{abstract}
The election process becomes very important in determining the desired outcome for the voters. The election process is often hampered by a variety of issues, such as the process of gathering and recounting the result sometimes takes time. For that we need a system that can facilitate the selection process so that it can provide quick and accurate results. The purpose of this study is to build a system that can provide convenience for students of the Faculty of Information Technology UNAI in running the democratic process to select the Chairman of the Student Association. The system is designed webbased so it will be easier in the process of taking voting, vote counting and announcement of the selected winners. The method used in building this system is using SDLC method with Waterfall model which consists of stages of Analysis, Design, Implementation and Maintenance. The results of the design of this system can be used in selecting the pair chairman and vice chairman of Student Association Faculty of Information Technology UNAI. The election process can run more orderly, regularly and faster especially in vote counting and winner announcement because it is done through the system. It is expected that in the future this system can be developed and applied to other election process and can be made on other platforms.
\end{abstract}

\section{Latar Belakang}

Sebuah organisasi wajib memiliki struktur kepemimpinan. Pemimpin merupakan faktor yang sangat menentukan keberhasilan suatu organisasi dalam mencapai tujuannya. Himpunan Mahasiswa Jurusan (HIMA) adalah organisasi kemahasiswaan di tingkat jurusan di suatu perguruan tinggi/universitas. Himpunan ini merupakan media bagi anggotanya untuk mengembangkan pola pikir dan kepribadian yang berkaitan dengan disiplin ilmunya agar siap terjun ke masyarakat. Metode 
Rancang Bangun Sistem E-Voting Berbasis Web

pemilihan (voting) pemimpin HIMA Fakultas Teknologi Informasi Universitas Advent Indonesia (UNAI) selama ini dilakukan dengan cara konvensional, yaitu mahasiswa sebagai pemilih (voters) akan dikumpulkan di suatu tempat dan akan menyalurkan suaranya dengan cara yang telah ditentukan. Metode ini tentu saja menimbulkan potensi terjadinya kecurangan dan kurang mewakili seluruh mahasiswa fakultas karena tidak semua pemilih dating ke tempat pemilihan, selain itu metode ini tentu saja sangat tertinggal ditengah era kemajuan teknologi informasi saat ini.

Perkembangan teknologi saat ini telah membawa berbagai kemudahan bagi manusia, termasuk dalam melaksanakan voting. Penggunaan teknologi komputer dalam melaksanakan voting disebut dengan electronic voting atau biasa disebut e-voting. Terdapat banyak cara untuk mengimplementasikan evoting, diantaranya dengan penggunaan internet seperti voting dari web, penggunaan touch screen untuk mengganti kertas suara, dan masih banyak lagi.

\section{Konsep Dasar Sistem, data dan Informasi}

Sistem adalah kumpulan dari sub system atau komponen baik fisik ataupun non fisik yang saling berhubungan satu dengan yang lain dan bekerja sama secara harmonis untuk mencapai satu tujuan tertentu (Susanto, 2013). Data merupakan informasi umum yang belum disaring sedangkan informasi merupakan data yang telah berkembang ke titik yang lebih berguna untuk beberapa bentuk yang sudah dianalisis (Liew, 2007). Menurut Susanto (2013) bahwa sistem mempunyai tujuan sebagai berikut: "Tujuan sistem merupakan target atau sasaran akhir yang ingin dicapai oleh suatu sistem. Agar supaya target tersebut bisa tercapai, maka target atau sasaran tersebut harus diketahui terlebih dahulu ciri-ciri atau kriterianya. Upaya mencapai suatu sasaran tanpa mengetahui ciri-ciri atau kriteria dari sasaran tersebut kemungkinan besar sasaran tersebut tidak akan pernah tercapai. Ciri-ciri atau kriteria dapat juga digunakan sebagai tolak ukur dalam menilai suatu keberhasilan suatu sistem dan menjadi dasar dilakukannya suatu pengendalian ".

Apabila kata sistem digabungkan dengan kata informasi maka pengertian dan fungsinya akan berubah. Sistem informasi dapat diartikan menjadi sebuah alat untuk yang dapat menyajikan informasi bermanfaat bagi penerimanya dengan memberikan informasi dalam perencanaan, pengorganisasian, serta operasional sebuah perusahaan yang dapat digunakan oleh organisasi dalam proses pengambilan pengambilan keputusan (Kertahadi, 2007). Sistem informasi adalah "Sistem dapat didefinisikan dengan mengumpulkan, memperoses, menyimpan, menganalisis, menyebarkan informasi untuk tujuan tertentu. Seperti sistem lainnya, sebuah sistem informasi terdiri atas input (data, instruksi) dan output (laporan, kalkulasi)" (Sutarman, 2012).

\section{Analisis Sistem}

Saat ini voting pemimpin HIMA Fakultas Teknologi Informasi UNAI masih dilakukan dengan cara konvensional, yaitu mahasiswa sebagai pemilih (voters) akan dikumpulkan di suatu tempat dan akan menyalurkan suaranya dengan cara voting secara langsung/tunjuk tangan. Metode ini tentu saja menimbulkan potensi terjadinya kecurangan, pemilih dapat memilih lebih dari 1 kali, pemilih yang memilih hanya karena mengikuti pendapat teman dan kurang mewakili seluruh mahasiswa fakultas karena tidak semua pemilih datang ke tempat pemilihan, selain itu metode ini tentu saja sangat tertinggal ditengah era kemajuan teknologi informasi saat ini.

Melalui sistem e-voting ini voters yang terdaftar sebagai mahasiswa Fakutas Teknologi Informasi UNAI dapat melakukan voting melalui web dengan terlebih dahulu memasukkan NIM dan password yang digunakan pada modul kuliah masing-masing.

\section{Perancangan Sistem}

Sistem ini diharapkan dapat mengatasi masalah dan kesulitan yang dihadapi saat ini oleh sehingga pemilihan HIMA dapat dilaksanakan dengan efektif dan efisien.

Berikut beberapa usulan untuk memperbaiki sistem pemilihan pemimpin HIMA, yaitu membuat sistem informasi yang dapat digunakan untuk memilih pemimpin HIMA, 
Perancangan sistem ini menggunakan diagram UML (Unified Modeling Language). Dari perancangan use case yang dilakukan, terlihat bahwa sistem yang dirancang dapat melakukan pengelolaan data dosen, pengelolaan tingkatan rapat, pengelolaan kategori rapat, pencarian surat, pengelolaan rapat, pengelolaan absensi, pengelolaan keputusan serta pengiriman hasil keputusan rapat seperti terlihat pada gambar 1 .

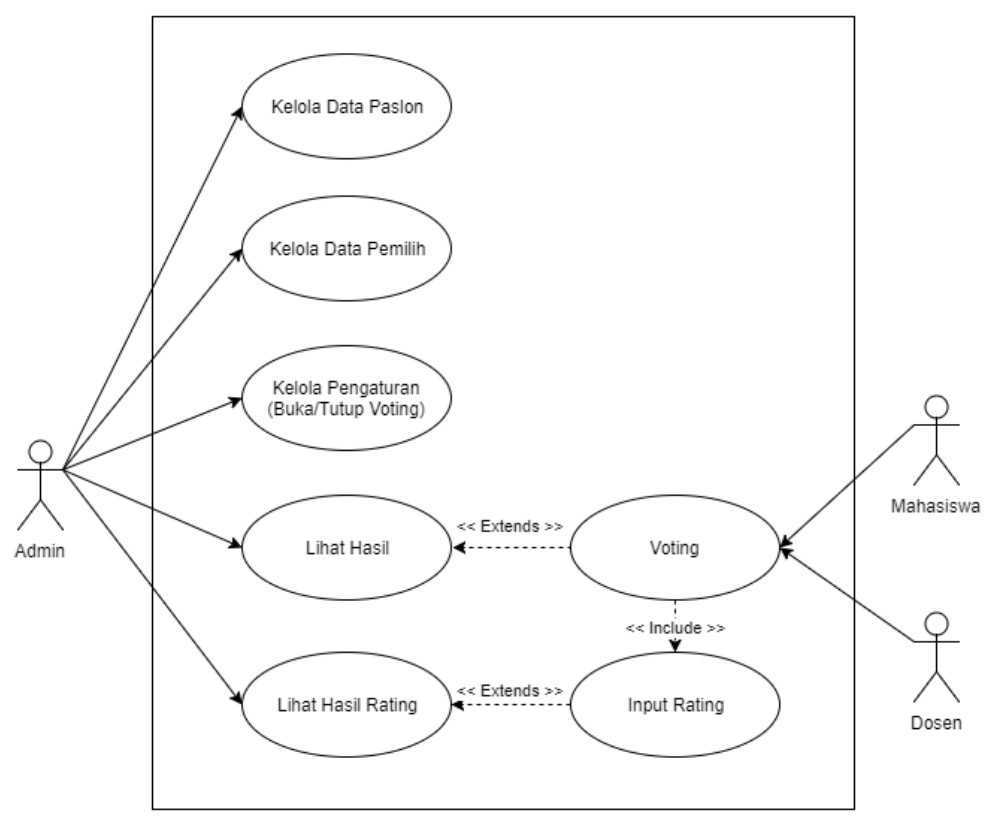

Gambar 1 Use Case Diagram

\section{Tampilan Antar Muka Pengguna}

Gambar dibawah ini merupakan tampilan awal/home. Tampilan ini menunjukkan pasangan calon yang akan berkompetisi untuk mendapatkan suara dari para pemilih beserta detail calon mulai dari nama lengkap, fakultas/jurusan, indeks prestasi kumulatif, visi dan misi dari masing-masong pasangan calon. Terdapat juga petunjuk pemilihan bagi para calon pemilih untuk memilih pasangan yang diinginkan.

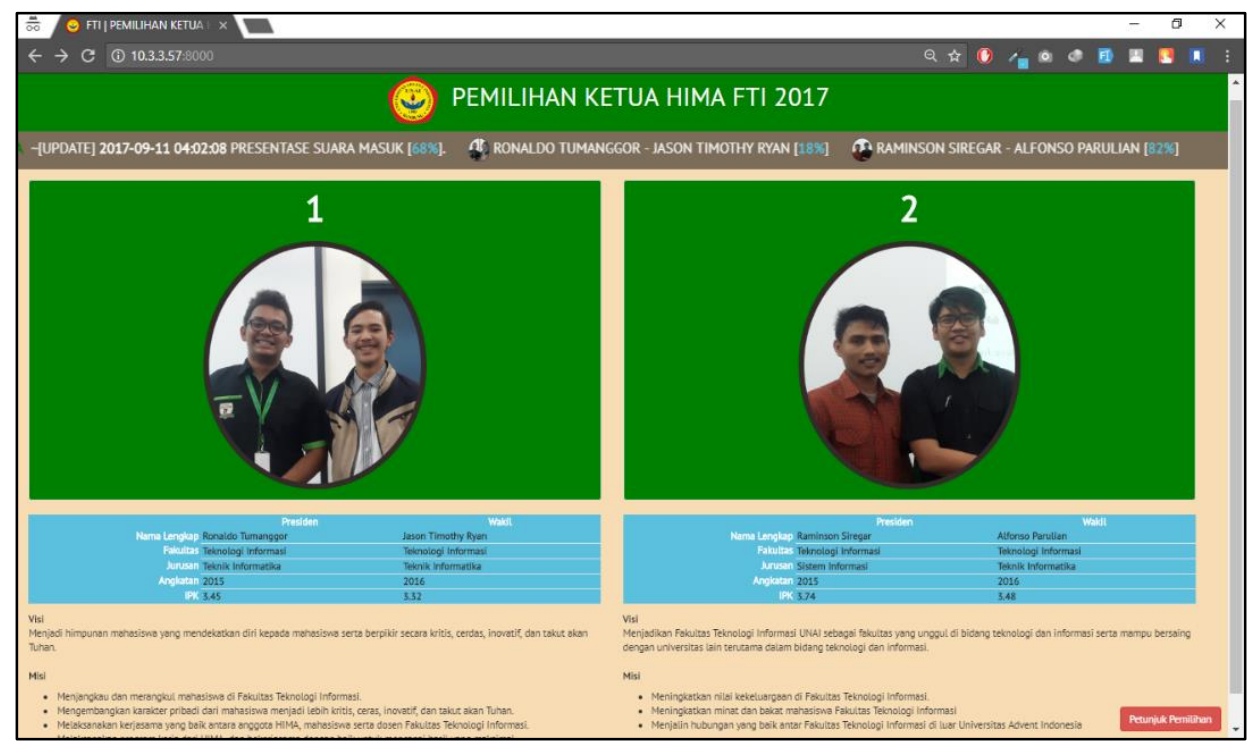


Gambar 2 Tampilan Halaman Utama/Home

Gambar 3 dibawah ini merupakan tampilan login pemilih. Pemilih diharuskan memasukkan nomor induk mahasiswa (NIM), tempat lahir dan password sesuai dengan yang telah didaftarkan pada modul Universitas Advent Indonesia. Setelah pemilih memasukkan NIM dan password maka mereka dapat mengklik tombol Vote untuk meneruskan pilihannya. Satu NIM hanya dapat melakukan satu kali pemilihan.

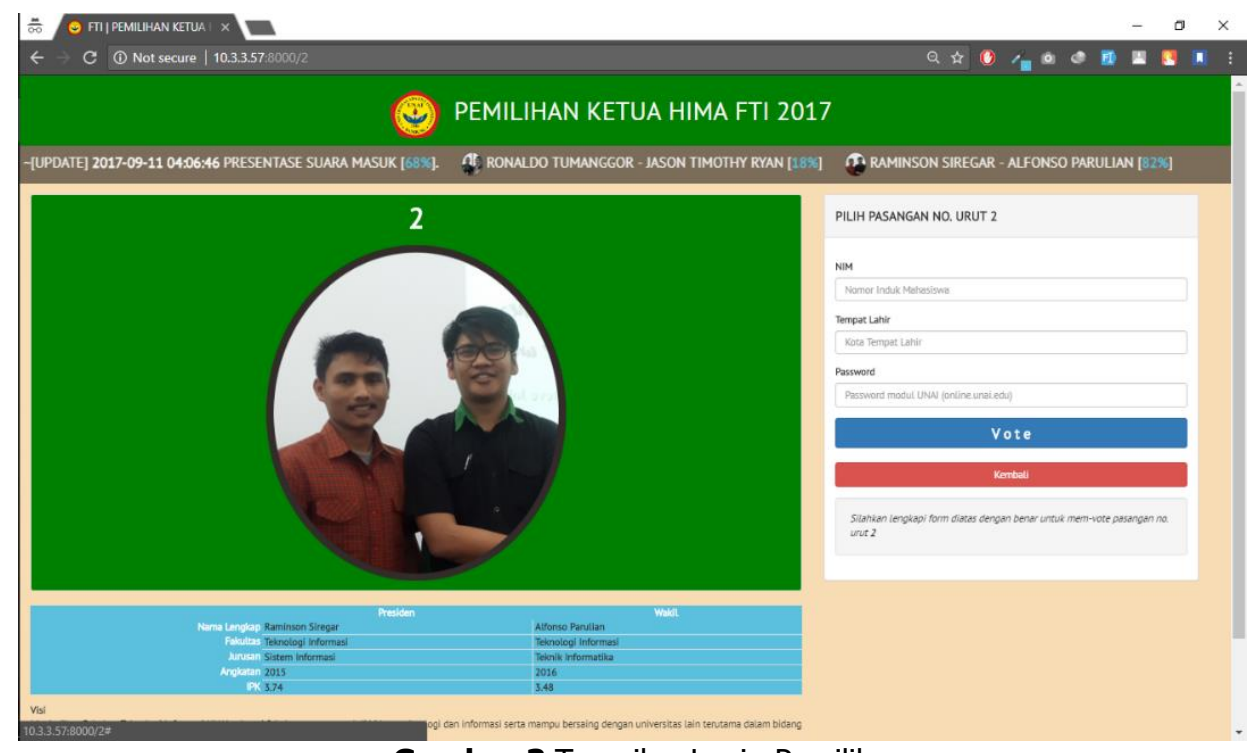

Gambar 3 Tampilan Login Pemilih

\section{Tampilan Antar Muka Admin}

Admin merupakan pengguna pertama pada sistem ini. Gambar 4 dibawah ini merupakan tampilan login admin. Admin harus memasukkan Email dan Password untuk dapat masuk ke menu utama sistem ini. Setelah login admin dapat melakukan pengaturan penggunaan aplikasi.

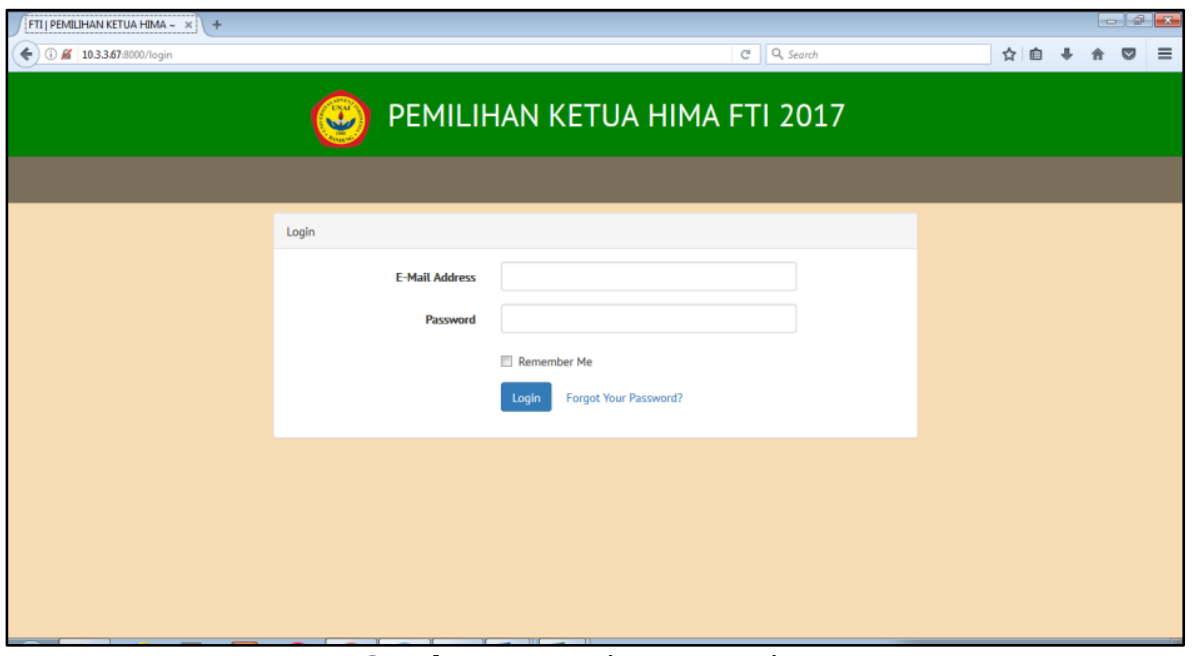

Gambar 4 Tampilan Login Admin

Gambar 5 dibawah ini merupakan pengaturan admin dalam membuka dan menutup waktu voting yang akan atau sedang berlangsung. Voting akan dibuka dari sistem untuk waktu yang sudah ditentukan. Ketika voting sudah status buka, maka semua pemilih sudah dapat menentukan pilihannya melalui 
sistem dengan mengklik pada gambar pasangan yang diinginkan. Data setiap pemilih akan disimpan dalam sistem. Update hasil pemilihan akan ditampilkan di layar berupa persentasi perolehan suara dari semua pemilih yang sudah melakukan pilihannya. Ketika waktu pemilihan telah selesai maka sistem ditutup oleh admin. Ketika sistem sudah ditutup maka pemilih tidak dapat lagi melakukan login ke sistem. Setelah sistem ditutup maka pengumuman pemenang dapat ditampilkan di web sehingga seluruh pihak yang berkepentingan dapat melihat hasil pemilihan tersebut

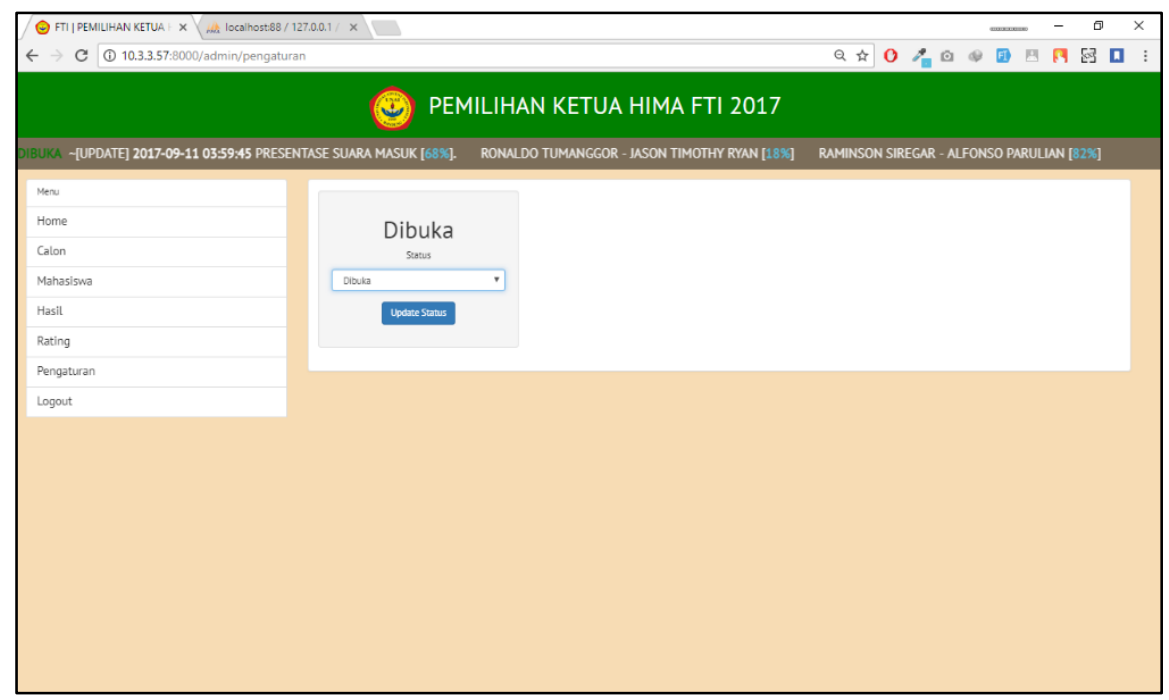

Gambar 5 Tampilan Pengaturan Admin

\section{Kesimpulan dan Saran}

Berdasarkan hasil penelitian yang sudah dilakukan dengan merancang dan membangun serta mengimplementasikan sistem e-voting ini, maka didapatkan kesimpulan bahwa sistem informasi evoting yang dibuat dapat membantu mengelola proses pemilihan ketua dan wakil ketua Himpunan Mahasiwa Fakultas Teknologi Informasi UNAI. Proses pemilihan dilakukan lebih teratur, lebih cepat, lebih aman dan lebih akurat dimana semua pemilih dapat melakukan login dan menentukan pilihannya dengan memilih pasangan calon yang ada pada sistem. Hasil dari pemilihan tersebut juga dengan cepat dan akurat dapat dilihat oleh semua pihak yang berkepentingan. Dalam penerapannya sistem informasi ini juga dapat diterapkan pada proses pemilihan yang lain dengan menyesuaikan beberapa fitur sesuai dengan kebutuhan serta dapat pula dikembangkan dalam platform yang lain seperti aplikasi mobile.

\section{Referensi}

1. Susanto, Azhar, 2013. "Sistem Informasi Akuntansi". Bandung: Lingga Jaya.

2. Liew, Anthony, 200. "Understanding Data, Information, Knowledge And Their Inter-Relationships". Journal of Knowledge Management Practice, Vol. 8, No. 214

3. Sutarman, 2012."Pengantar Teknologi Informasi".Jakarta: Bumi Aksara

4. Kertahadi, 2007. "Dasar-Dasar Sistem Informasi". Yogjakarta: STIKOM. 